\title{
Efeito da luz na germinação in vitro de embriões zigóticos de genótipos de oliveira
}

\author{
Rafaeli Aparecida Vieira de Souza ${ }^{1}$, Francyane Tavares Braga ${ }^{2}$, Patrícia Helena de Azevedo ${ }^{3}$, \\ Juliano Lino Ferreira ${ }^{4}$, Geraldo Magela de Almeida Cançado ${ }^{5 *}$
}

\section{RESUMO}

O objetivo deste trabalho foi avaliar o efeito da luz na germinação e desenvolvimento in vitro de embriões de 11 genótipos de oliveira, cultivados em meio MS. Os frutos foram coletados e os embriões de suas sementes extraídos assepticamente. Utilizaram-se duas condições experimentais de incubação: presença de luz, fornecida em sala de crescimento, com 16 h de luz com irradiância média de $36 \mu \mathrm{mol} \mathrm{m}{ }^{-2} \mathrm{~s}^{-1}$, e ausência de luz, simulada em câmara de germinação tipo B.O.D.; ambos os tratamentos em temperatura de $25^{\circ} \mathrm{C}$. Inicialmente, caracterizaram-se morfologicamente os frutos e sementes dos genótipos de oliveira, com medição do comprimento e diâmetro. Avaliaram-se o índice de velocidade de germinação (IVG), percentagem de germinação, comprimento de parte aérea, número de folhas e entrenós das plântulas. Maior IVG e percentagem de germinação foram observados em condições de incubação, na presença de luz para o genótipo 'Cerignola 131’. Maior comprimento de parte aérea e maior número de folhas e de entrenós das plântulas foram observados no genótipo ‘Salomé 488’, independentemente da condição de incubação.

Palavras-chave: Olea europaea L., cultivo de embriões, olivicultura, sementes, propagação sexuada.

\section{ABSTRACT}

\section{Effect of light on germination in vitro of zygotic embryos of olive genotypes}

The purpose of this study was to evaluate the influence of light in the in vitro development of embryos from eleven olive genotypes on MS medium. The fruits were collected, and their embryos were extracted aseptically. Two experimental conditions of incubation were used: the presence of light, in a growth room at $25 \pm 1^{\circ} \mathrm{C}$, irradiance of 36 $\mu \mathrm{mol} \mathrm{m} \mathrm{m}^{-1}$ and a photoperiod of 16 hours, and the absence of light using BOD temperature of $25^{\circ} \mathrm{C}$. The germination was evaluated (speed index and percentage ratio) at the $10^{\text {th }}$ day of incubation. Additionally, at the $45^{\text {th }}$ day, the shoot length, the number of leaves and the internodes of seedlings were recorded. The best speed index and germination percentage occurred in conditions of incubation in the presence of light. The genotype 'Salome', access 488, presented the greatest shoot length, and the highest number of leaves and internodes, independent of the incubation condition.

Key words: Olea europaea L., embryo culture, olive, seeds, sexual propagation.

\footnotetext{
Recebido para publicação em 05/10/2011 e aprovado em 13/04/2012

Artigo proveniente da tese de mestrado do primeiro autor.

${ }^{1}$ Engenheira-Agrônoma, Mestre. Departamento de Agronomia, Universidade Federal de Mato Grosso, Av. Fernando Corrêa da Costa, 2367, Bairro Boa Esperança, 78060-900, Cuiabá, Mato Grosso, Brasil. rafaeliap@yahoo.com.br

${ }^{2}$ Engenheira-Agrônoma, Doutora. Departamento de Educação, Universidade do Estado da Bahia, Campus VIII, Rua Gangorra, 503, General Dutra, 48608-240, Paulo Afonso, Bahia, Brasil. bragaft@yahoo.com.br

${ }^{3}$ Engenheiras-Agrônomas, Doutoras. Departamento de Agronomia, Universidade Federal de Mato Grosso. Av. Fernando Corrêa da Costa, 2367, Bairro Boa Esperança, 78060900 Cuiabá, Mato Grosso, Brasil. patriciaazevedo@cpd.ufmt.br,azevedovh@yahoo.com.br

${ }^{4}$ Engenheiro-Agrônomo, Doutor. Pesquisador da Empresa Brasileira de Pesquisa Agropecuária - Embrapa Pecuária Sul, BR 153 Km 603, Vila Industrial, 96401-970, Bagé, Rio Grande do Sul, Brasil. julianolf@gmail.com

${ }^{5}$ Engenheiro-Agrônomo, Doutor. Pesquisador da Empresa de Pesquisa Agropecuária de Minas Gerais, Laboratório de Biotecnologia Vegetal, Av. Santa Cruz, 500, Bairro Santa Cruz, 37780-000, Caldas, Minas Gerais, Brasil. cancado@epamig.br (*autor para correspondência)
} 


\section{INTRODUÇÃO}

A oliveira (Olea europaea L.) é uma espécie perene, amplamente cultivada e apreciada em todo o mundo, com grande importância no mercado alimentício, pois seus produtos, o azeite e o fruto para consumo de mesa, são amplamente difundidos em centenas de países, incluindo o Brasil.

Convencionalmente, essa espécie é propagada vegetativamente, por técnicas de enxertia e estaquia de mudas. A propagação por sementes não é aconselhável, em função do longo período juvenil, além da baixa germinação em condições de campo, inviabilizando a propagação comercial (Binet et al., 2007).

As técnicas de cultura de tecidos in vitro surgem como ferramenta capaz de solucionar tais problemas, diminuindo o tempo de produção e obtendo plantas homogêneas e livres de doenças, além de ser uma oportunidade para aperfeiçoar os processos de melhoramento genético e de propagação desta espécie (Rugini \& Caricato, 1995).

Diversas técnicas e meios de cultura foram desenvolvidos para obter plântulas in vitro de oliveira (Oliveira, 2001). Entre as técnicas, a cultura de embriões in vitro, além de reduzir o tempo para obtenção de um novo indivíduo, garante alto percentual de germinação. Embora não seja uma opção adequada para a propagação comercial, por causa da segregação genética, o cultivo de embriões é de grande importância para várias áreas de estudo, com destaque para os do melhoramento genético, da fisiologia e da bioquímica vegetal. Um aspecto fundamental para esses processos é o domínio da tecnologia de propagação em laboratório, que é o resultado de estudos conduzidos com os fatores que afetam o crescimento e o desenvolvimento dessas plantas in vitro.

A luz é um fator importante para o desenvolvimento das plantas, seja por ação direta ou indireta na regulação do seu metabolismo (Erig \& Schuch, 2005). No entanto, os efeitos da luz sobre o desenvolvimento embrionário são pouco estudados, para muitas espécies. Sabe-se que a luz pode ter ação benéfica sobre as sementes, por estimular a síntese de hormônios e enzimas, controlar a taxa respiratória e a permeabilidade dos tegumentos ao oxigênio, entre outros aspectos (Bewley \& Black, 1994).

Diante disso, o objetivo deste trabalho foi avaliar a influência da luz, na germinação e no desenvolvimento in vitro de embriões zigóticos de 11 genótipos de oliveira.

\section{MATERIAL E MÉTODOS}

\section{Local de estudo e coleta de material vegetal}

O experimento foi desenvolvido no Laboratório de Biotecnologia Vegetal da Empresa de Pesquisa Agropecuária de Minas Gerais (Epamig), localizado em Caldas, MG, utilizando-se frutos de 11 genótipos de oliveira, sendo eles: 'Alto D’ouro', 'Halhali 0063', 'Penafiel SP', 'Koroneike 0007', 'Cerignola 131', 'Grappolo 575', 'Grappolo 561', 'Salomé 488', 'Manzanilla 215’, ‘Ascolano 315' e 'Mission'. Os frutos foram colhidos no banco de germoplasma de oliveira, localizado na Fazenda Experimental da Epamig, em Maria da Fé, MG, situada na latitude

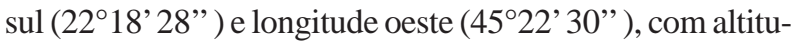
de média de $1.258 \mathrm{~m}$ e clima tropical de altitude Cwb.

Os frutos foram coletados quando atingiram maturação fisiológica, que foi determinada pela coloração marrom arroxeada do fruto.

Antes da instalação do experimento, foi realizada a caracterização dos frutos dos 11 genótipos utilizados, sendo usados 30 frutos por genótipo, avaliando-se as seguintes características: comprimento e diâmetro dos frutos e das sementes. Para isso, utilizou-se um paquímetro digital.

\section{Esterilização do material vegetal e germinação in vitro dos embriões}

Os frutos foram despolpados e as sementes lavadas em água corrente e secas à sombra. Em seguida, procedeu-se à assepsia superficial, com álcool a 70\%, por quinze minutos. Antes da instalação do experimento, as sementes permaneceram em condições de baixas temperaturas, de 3 a $5^{\circ} \mathrm{C}$, por 5 dias.

A extração do embrião foi feita pela quebra do endocarpo e retirada do albúmen (Figura 1). O albúmen passou por processo de assepsia superficial em câmara asséptica de fluxo laminar, com álcool a 70\%, durante 30 segundos e, posteriormente, em hipoclorito de sódio 1\%, por 20 min, seguido de tríplice lavagem em água destilada e autoclavada.

Para a germinação in vitro dos embriões, utilizou-se meio de cultivo MS (Murashige \& Skoog, 1962), acrescido de 30 g. $L^{-1}$ de sacarose e 6 g.L ${ }^{-1}$ de ágar. $\mathrm{O}$ pH do meio foi ajustado para 5,8, antes da autoclavagem, realizada a $121^{\circ} \mathrm{C}$ e 1,2 atm por $20 \mathrm{~min}$. Cada tubo de ensaio recebeu $10 \mathrm{~mL}$ de meio de cultivo.

Os embriões foram incubados em dois diferentes ambientes: 1) ausência de luz, utilizando-se de câmara de germinação tipo B.O.D., com temperatura constante de $25^{\circ} \mathrm{C}$, durante sete dias; e 2) presença de luz, caracterizada pelo uso de sala de crescimento com temperatura de $25 \pm 1^{\circ} \mathrm{C}$ e fotoperíodo de $16 \mathrm{~h}$ de luz, com irradiância de $36 \mu \mathrm{mol} \mathrm{m}{ }^{-2} \mathrm{~s}^{-1}$, durante sete dias.

A avaliação do índice de velocidade de germinação (IVG) foi feita, diariamente, do primeiro dia após instalação do experimento até o sétimo dia após inoculação dos embriões ao meio de cultivo determinado segundo a metodologia descrita por Maguire (1962). Logo após essa avaliação, os embriões sob condições de ausência de luz 


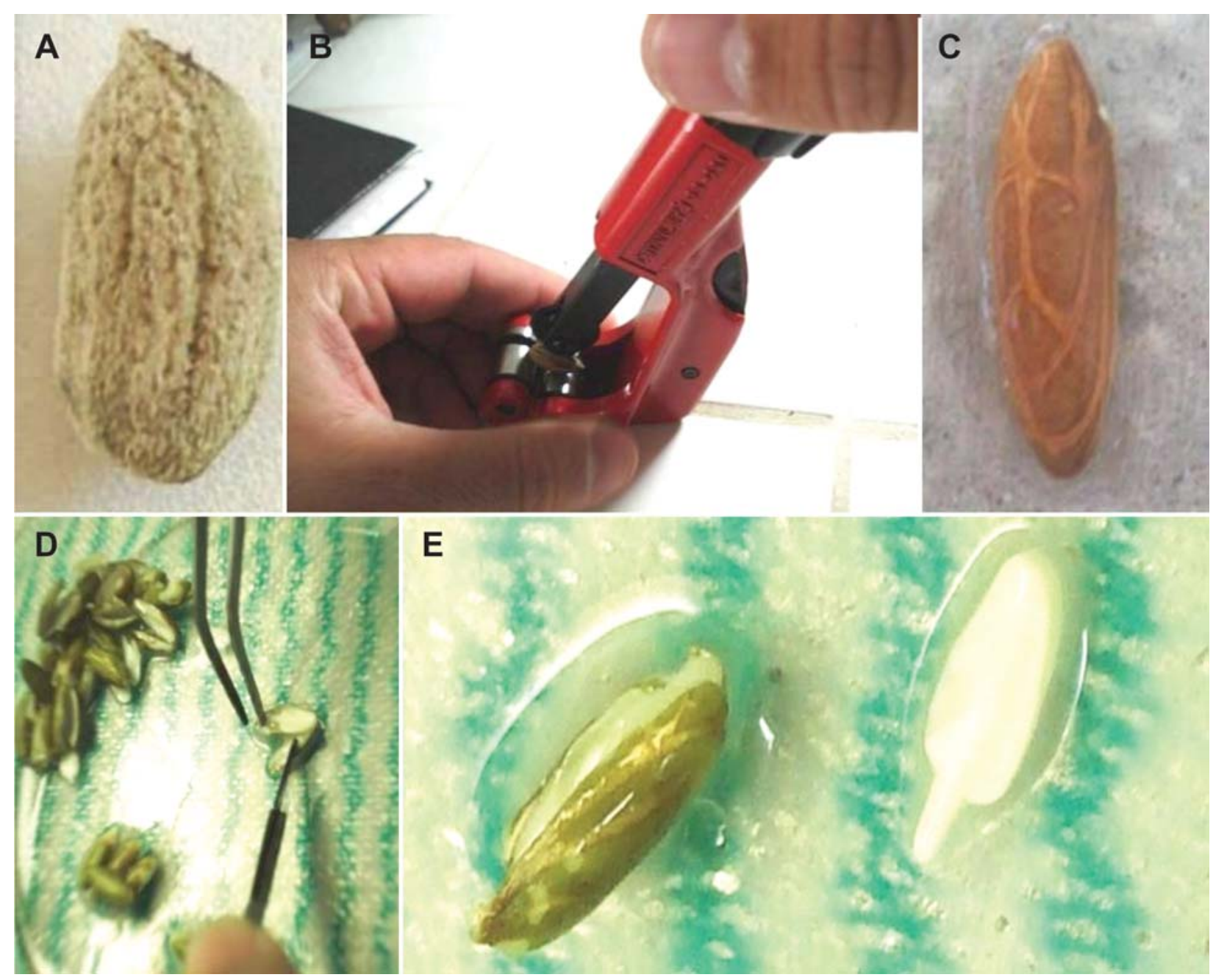

Figura 1. Extração do embrião de oliveira. A) semente; B) extrator do albúmen; C) albúmen; D) separação do embrião em câmara de fluxo laminar; E) embrião.

(B.O.D.) foram transferidos para sala de crescimento. Aos dez dias de incubação, avaliou-se o percentual de germinação e, aos 45 dias, avaliaram-se o comprimento da parte aérea e o número de folhas e entrenós por plântula.

\section{Delineamento experimental}

O delineamento experimental foi o inteiramente casualizado, em esquema fatorial 11 x 2, sendo 11 genótipos de oliveira e 2 ambientes de incubação (presença e ausência de luz), compostos por três repetições de quatro tubos de ensaio, contendo um embrião cada.

Utilizou-se o software Sisvar 5.0 (Ferreira, 2008) para as análises de variância, e as médias foram comparadas pelo teste de Scott \& Knott a 5\% de probabilidade. Foram feitas análises multivariadas com objetivo de ordenar e agrupar os dados, utilizando o software Genes (Cruz, 2006). O termo análise multivariada refere-se à análise conjunta de diversas características, simultaneamente, possibilitando integrar as múltiplas informações extraídas das avaliações experimentais.
Foi estudada a importância de caracteres (Singh, 1981), levando-se em consideração a distância padronizada de Mahalanobis $\left(\mathrm{D}^{2}\right)$. Foi feita também a matriz de dissimilaridade e, posteriormente, o agrupamento, utilizando o método hierárquico (UPGMA).

\section{RESULTADOS E DISCUSSÃO}

Os frutos e sementes dos 11 genótipos de oliveira apresentaram diferenças significativas em relação ao tamanho (Tabela 1). O genótipo ‘Cerignola 131' apresentou o maior tamanho de fruto e semente, em relação aos outros genótipos estudados. A classificação das sementes por tamanho, para determinação da qualidade fisiológica, tem sido bastante empregada na multiplicação das diferentes espécies vegetais (Frazão et al., 1983).

Na germinação in vitro dos genótipos de oliveira, foram observados, no terceiro dia, abertura e enverdecimento dos cotilédones; no quinto dia, início da germinação; e no décimo dia, total protrusão radicular, para os genótipos incubados na presença de luz. Não foram ob- 
Tabela 1. Caracterização morfológica de frutos e sementes de 11 genótipos de oliveira

\begin{tabular}{lcccc}
\hline Genótipos & $\begin{array}{c}\text { Comprimento médio } \\
\text { do fruto }(\mathbf{m m})\end{array}$ & $\begin{array}{c}\text { Diâmetro médio do } \\
\text { fruto } \mathbf{( m m})\end{array}$ & $\begin{array}{c}\text { Comprimento médio } \\
\text { da semente } \mathbf{( m m})\end{array}$ & $\begin{array}{c}\text { Diâmetro médio } \\
\text { da semente }(\mathbf{m m})\end{array}$ \\
\hline Salomé 448 & $15,28 \mathrm{e}$ & $11,00 \mathrm{e}$ & $11,57 \mathrm{e}$ & $6,36 \mathrm{~g}$ \\
Koroneike 0007 & $16,58 \mathrm{~d}$ & $12,76 \mathrm{~d}$ & $11,96 \mathrm{e}$ & $6,17 \mathrm{~g}$ \\
Grappolo 575 & $16,97 \mathrm{~d}$ & $12,99 \mathrm{~d}$ & $14,70 \mathrm{c}$ & $7,05 \mathrm{e}$ \\
Manzanilla 215 & $17,93 \mathrm{c}$ & $14,53 \mathrm{c}$ & $13,66 \mathrm{~d}$ & $8,60 \mathrm{a}$ \\
Mission & $18,13 \mathrm{c}$ & $12,58 \mathrm{~d}$ & $14,45 \mathrm{c}$ & $6,70 \mathrm{f}$ \\
Grappolo 561 & $18,26 \mathrm{c}$ & $13,47 \mathrm{~d}$ & $13,57 \mathrm{~d}$ & $7,66 \mathrm{~b}$ \\
Alto D'ouro & $18,43 \mathrm{c}$ & $12,75 \mathrm{~d}$ & $14,49 \mathrm{c}$ & $7,46 \mathrm{c}$ \\
Penafiel SP & $18,82 \mathrm{c}$ & $14,42 \mathrm{c}$ & $13,80 \mathrm{~d}$ & $8,00 \mathrm{~b}$ \\
Halhali 0063 & $20,95 \mathrm{~b}$ & $15,97 \mathrm{~b}$ & $15,40 \mathrm{~b}$ & $8,66 \mathrm{a}$ \\
Ascolano 315 & $21,26 \mathrm{a}$ & $15,16 \mathrm{c}$ & $16,29 \mathrm{a}$ & $8,33 \mathrm{a}$ \\
Cerignola 131 & $23,58 \mathrm{a}$ & $18,06 \mathrm{a}$ & $16,90 \mathrm{a}$ & 7,07 \\
\hline CV (\%) & 7,81 & 8,97 & 8,62 & \\
\hline
\end{tabular}

* Médias seguidas da mesma letra não diferem entre si pelo teste de Scott \& Knott a 5\% de probabilidade.

servados enverdecimento dos cotilédones nos embriões incubados na ausência de luz, na câmara de germinação tipo B.O.D., por estar a síntese de clorofila condicionada à presença de luz.

Para percentagem de germinação, não houve diferença significativa para o fator genótipos e para a interação genótipos x ambientes de incubação. Porém, vale ressaltar que, numericamente, a maior percentagem de germinação in vitro de oliveira foi observada para o genótipo 'Cerignola 131' (73,33\%). Os resultados foram significativos apenas para o fator ambiente de incubação, no qual a presença de luz apresentou maior percentagem de germinação, quando comparada com a da ausência de luz (Tabela 2). A maior percentagem de germinação para o genótipo ‘Cerignola 131' correlaciona-se com o maior tamanho de fruto e semente para o mesmo genótipo. As sementes de maior tamanho geralmente foram mais bem nutridas durante o seu desenvolvimento, possuindo embriões bem formados e com maior quantidade de substâncias de reserva, sendo, consequentemente, as mais vigorosas (Carvalho \& Nakagawa, 2000).

Popinigis (1985) comentou que o tamanho da semente, em muitas espécies, é indicativo de sua qualidade fisiológica e que as sementes pequenas, dentro de um mesmo lote, apresentam menor germinação e vigor do que as médias e grandes. Complementando, Gray et al. (1986) comentaram que as sementes maiores supostamente seriam as que receberam maior quantidade de assimilados durante o seu desenvolvimento, apresentando embriões bem formados, com maiores quantidades de reserva, sendo, potencialmente, as mais vigorosas.

As sementes podem ser classificadas de acordo com sua resposta à luz como fotoblásticas positivas, beneficiadas pela luz; fotoblásticas negativas, prejudicadas pela luz; e não fotoblásticas ou indiferentes, cuja sensibilidade a esse fator não interfere na germinação. Observou-se, pelos resultados, que genótipos de oliveira apresentaram melhores percentagens de germinação quando os embriões foram inicialmente expostos à luz.

A importância da luz na germinação faz-se presente pela fotorreação, que controla a germinação por meio de um pigmento (fitocromo) presente no citoplasma de células do eixo embrionário, cuja forma ativa é convertida pela exposição à luz, disparando o processo de germinação pela síntese de hormônios e enzimas, controle respiratório, permeabilidade dos tegumentos ao oxigênio e metabolismo de lipídios (Taiz \& Zeiger, 2008). Porém, a intensidade desses efeitos dependerá da espécie e do cultivar, além de outros fatores relacionados com o processo de germinação.

Martinotto et al. (2007) testaram o efeito da escarificação do tegumento e a presença e ausência de luz, na ger-

Tabela 2. Percentagem de germinação de embriões in vitro de genótipos de oliveira em diferentes ambientes de incubação

\begin{tabular}{lc}
\hline Tratamento & Germinação (\%) \\
\hline Ausência de luz & $50,74 \mathrm{~b}$ \\
Presença de luz & $65,55 \mathrm{a}$ * \\
\hline Genótipos & Germinação (\%) \\
\hline Alto D’ouro & $50,00 \mathrm{a}$ \\
Koroneike 0007 & $50,00 \mathrm{a}$ \\
Salomé 488 & $50,00 \mathrm{a}$ \\
Ascolano 315 & $56,66 \mathrm{a}$ \\
Grappolo 575 & $60,00 \mathrm{a}$ \\
Mission & $63,33 \mathrm{a}$ \\
Halhali 0063 & $63,33 \mathrm{a}$ \\
Penafiel SP & $66,66 \mathrm{a}$ \\
Manzanilla 215 & $66,66 \mathrm{a}$ \\
Grappolo 561 & $66,66 \mathrm{a}$ \\
Cerignola 131 & $73,33 \mathrm{a}$ \\
\hline CV (\%) & 47,04
\end{tabular}

* Médias seguidas da mesma letra não diferem entre si pelo teste de Scott \& Knott a 5\% de probabilidade. 
minação in vitro de cagaiteira (Eugenia dysenterica DC.), e verificaram que a ausência de luz no período inicial do processo germinativo diminuiu a percentagem de germinação dessa espécie, corroborando os resultados apresentados para oliveira.

Resultados semelhantes foram obtidos por Leite \& Hebling (2007), trabalhando com orquídeas do gênero Cattleya. Estes autores observaram que a presença de luz proporcionou maiores percentagens de germinação in vitro. O índice de velocidade de germinação (Tabela 3) apresentou diferenças significativas para a interação genótipos x ambientes de incubação. Os dados obtidos

Tabela 3. Índice de velocidade de germinação (IVG) em embriões in vitro de genótipos de oliveira em diferentes ambientes de incubação

\begin{tabular}{lcc}
\hline \multirow{2}{*}{ Genótipos } & \multicolumn{2}{c}{ IVG (dias) } \\
\cline { 2 - 3 } & Ausência de Luz & Presença de Luz \\
\hline Koroneike 0007 & $0,72 \mathrm{~Gb}$ & $3,03 \mathrm{Ca}$ \\
Alto D’ouro & $0,72 \mathrm{~Gb}$ & $2,32 \mathrm{Fa}$ \\
Grappolo 561 & $1,42 \mathrm{Fb}$ & $3,32 \mathrm{Aa}$ \\
Salomé 488 & $1,52 \mathrm{~Eb}$ & $1,72 \mathrm{Ha}$ \\
Manzanilla 215 & $1,62 \mathrm{Db}$ & $2,91 \mathrm{Da}$ \\
Halhali 0063 & $1,62 \mathrm{Db}$ & $3,16 \mathrm{Ba}$ \\
Penafiel SP & $1,65 \mathrm{Db}$ & $3,13 \mathrm{Ba}$ \\
Grappolo 575 & $1,67 \mathrm{Db}$ & $1,82 \mathrm{Ga}$ \\
Ascolano 315 & $1,91 \mathrm{Cb}$ & $2,32 \mathrm{Fa}$ \\
Mission & $2,17 \mathrm{Bb}$ & $2,33 \mathrm{Fa}$ \\
Cerignola 131 & $2,22 \mathrm{Ab}$ & $2,72 \mathrm{Ea}$ \\
\hline CV(\%) & 2,73 \\
*Médias seguidas da mesma letra maiúscula na coluna e, minúscula \\
na linha não diferem entre si pelo teste de Scott \& Knott a 5\% de \\
probabilidade.
\end{tabular}

com o índice de velocidade mostraram que o ambiente, na presença de luz, apresentou maiores índices, juntamente com os genótipos ‘Grappolo 561’, ‘Halhali 0063’ e ‘Penafiel SP', confirmando que a luz influencia positivamente na germinação de oliveira.

Na avaliação de comprimento da parte aérea e número de entrenós, não houve diferenças significativas para o fator ambiente de incubação e para a interação entre genótipos $\mathrm{x}$ ambientes de incubação, porém, o fator genótipo, isoladamente, apresentou diferenças significativas, conforme mostra a Tabela 4.

Para número de folhas, as médias foram significativas apenas para os dois fatores, isoladamente, não sendo significativa a interação entre os fatores. Para todas as variáveis de crescimento analisadas, o genótipo que apresentou maior média foi 'Salomé 488', seguido por ‘Grappolo 561'e ‘Grappolo 575' (Tabela 4).

O genótipo influenciou diretamente nas respostas do índice de velocidade e do percentual germinativo, assim como no crescimento e desenvolvimento da plântula, mostrando que para oliveira as respostas são específicas.

Em relação aos genótipos, o comportamento do dendrograma foi gerado em função das médias dos efeitos dos ambientes (presença e ausência de luz) e de genótipos, considerando-se todos os parâmetros avaliados, tendo sido formados dois grupos distintos: um contendo apenas o genótipo 'Salomé 488' e o outro grupo com os demais genótipos (Figura 2). Essa diferença, embora verificada apenas para um dos genótipos, confrontado com os demais, destaca a influência da variabilidade genética existente dentro da espécie Olea europaea.

Tabela 4. Desenvolvimento dos genótipos de oliveira cultivados in vitro na presença de luz após 45 dias de incubação

\begin{tabular}{lccc}
\hline Tratamento & $\begin{array}{c}\text { Comprimento } \\
\text { da parte aérea }(\mathbf{c m})\end{array}$ & Número de folhas & Número de entrenós \\
\hline Presença de luz & $3,92 \mathrm{a} *$ & $7,90 \mathrm{a}$ & $4,16 \mathrm{a}$ \\
Ausência de luz & $3,37 \mathrm{a}$ & $6,54 \mathrm{~b}$ & $3,56 \mathrm{a}$ \\
\hline Genótipos & $\begin{array}{c}\text { Comprimento } \\
\text { da parte aérea (cm) }\end{array}$ & Número de folhas & Número de entrenós \\
\hline Koroneike 0007 & $2,16 \mathrm{~b} *$ & $2,33 \mathrm{~b}$ \\
Mission & $2,91 \mathrm{~b}$ & $4,50 \mathrm{~b}$ & $3,33 \mathrm{~b}$ \\
Manzanilla 215 & $2,91 \mathrm{~b}$ & $6,33 \mathrm{~b}$ & $2,91 \mathrm{~b}$ \\
Cerignola 131 & $3,16 \mathrm{~b}$ & $5,50 \mathrm{~b}$ & $3,33 \mathrm{~b}$ \\
Penafiel Sp & $3,41 \mathrm{~b}$ & $6,16 \mathrm{~b}$ & $2,75 \mathrm{~b}$ \\
Ascolano 315 & $3,75 \mathrm{a}$ & $5,25 \mathrm{~b}$ & $3,66 \mathrm{~b}$ \\
Alto D’ouro & $4,00 \mathrm{a}$ & $7,25 \mathrm{~b}$ & $4,75 \mathrm{~b}$ \\
Halhali 0063 & $4,00 \mathrm{a}$ & $8,80 \mathrm{~b}$ & $3,75 \mathrm{~b}$ \\
Grappolo 575 & $4,16 \mathrm{a}$ & $7,08 \mathrm{~b}$ & $4,58 \mathrm{~b}$ \\
Grappolo 561 & $4,75 \mathrm{a}$ & $8,50 \mathrm{~b}$ & $3,83 \mathrm{~b}$ \\
Salomé 488 & $4,91 \mathrm{a}$ & $7,66 \mathrm{~b}$ & $7,25 \mathrm{a}$ \\
\hline CV (\%) & 51,43 & $13,16 \mathrm{a}$ & 52,94 \\
\hline
\end{tabular}

*Médias seguidas da mesma letra não diferem entre si, pelo teste de Scott \& Knott a 5\% de probabilidade. 
A separação do genótipo ‘Salomé 488’ dos demais (Figura 2) confirma os resultados apresentados nas tabelas de comparação de médias, para todas as variáveis de crescimento das plântulas analisadas.

A Tabela 5 apresenta a contribuição relativa de cada caráter na determinação da distância genética entre os genótipos de oliveira. A maior contribuição para separação dos grupos foi da variável número de entrenós (NE), com 75,19\%, seguida da variável número de folhas (NF), com 21,88\%. Nesta análise, observou-se a grande importância do parâmetro número de entrenós na formação dos agrupamentos. Observando-se a variável comprimento da parte aérea, verificou-se que ela não contribuiu consideravelmente para a formação dos grupos.
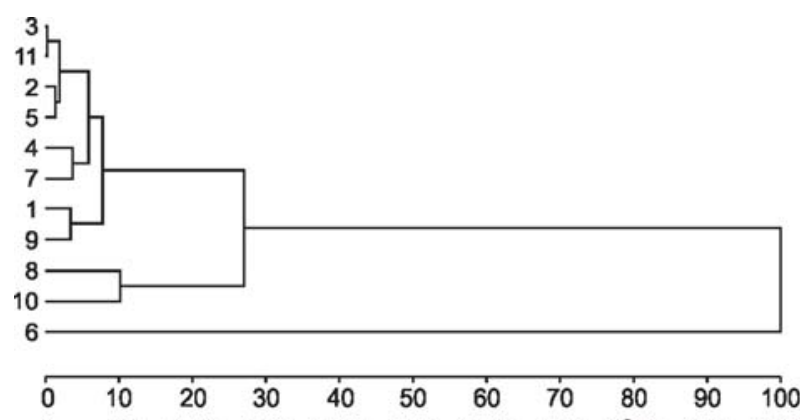

$\begin{array}{lllllllllll}0 & .79 & 1.59 & 2.38 & 3.18 & 3.97 & 4.77 & 5.56 & 6.36 & 7.15 & 7.95\end{array}$

Figura 2. Dendrograma da distância UPGMA entre 11 genótipos na análise multivariada: 1) Halhali 0063; 2) Cerignola 131; 3) Manzanilla 215; 4) Ascolano 314; 5) Mission; 6) Salomé 488; 7) Grappolo 575; 8) Grappolo 561; 9) Alto D’ouro; 10) Koroneike 0007; 11) Penafiel SP.

Tabela 5. Contribuição relativa (\%) dos caracteres comprimento de parte aérea (CPA), número de folhas (NF) e número de entrenós (NE) na análise de diversidade entre genótipos de oliveira cultivados em meio MS, utilizando a distância generalizada de Mahalanobis (D²), segundo Singh (1981)

\begin{tabular}{lrc}
\hline Variável & \multicolumn{1}{c}{ S.j } & Valor em \% \\
\hline CPA & 3,957422 & 2,92 \\
NF & 29,617996 & 21,88 \\
NE & 101,776828 & 75,19 \\
\hline
\end{tabular}

\section{CONCLUSÕES}

Os genótipos de oliveira tiveram a germinação positivamente influenciada pela presença de luz.

A maior percentagem de germinação para o genótipo 'Cerignola 131' correlaciona-se com o maior tamanho de fruto e de semente nesse genótipo.

A ausência de luz na fase inicial de germinação não influenciou no crescimento e desenvolvimento posterior das plântulas.

Maior comprimento da parte aérea e do número de folhas e entrenós foi observado no genótipo 'Salomé 488', independentemente da condição de luminosidade imposta na germinação.

\section{AGRADECIMENTOS}

Os autores agradecem o apoio financeiro concedido pela Fapemig, Finep, Capes, CNPq, Embrapa e a Fazenda Experimental da Epamig em Maria da Fé pelo fornecimento das sementes de oliveira.

\section{REFERÊNCIAS}

Bewley JD \& Black M (1994) Seeds: Physiology of development and germination. $1^{\mathrm{a}}$ ed. New York, Plenum Press. 445p.

Binet MN, Lemoine MC, Martin C, Chambon C \& Gianinazzi S (2007) Micropropagation of olive (Olea europaea L.) and application of mycorrhiza to improve plantlet establishment. In Vitro Cellular \& Development Biology Plant, 43:473-478.

Carvalho NM \& Nakagawa J (2000) Sementes: Ciência, tecnologia e produção. $4^{\text {a }}$ ed. Jaboticabal, Funep. 588p.

Cruz CD (2006) Programa Genes - Estatística experimental e matrizes. $1^{\text {a }}$ ed. Viçosa, Editora UFV. 285p.

Erig AC \& Schuch MW (2005) Tipo de luz na multiplicação in vitro de framboeseira (Rubus idaeus L.) “Batum”. Revista Brasileira de Fruticultura, 27:488-490.

Ferreira DF (2008) SISVAR: Um programa para análises e ensino de estatística. Revista Symposium, 6:36-41.

Frazão DAC, Figueirêdo FJC, Corrêia MPF, Oliveira, RP \& Popinigis F (1983) Tamanho da semente de guaraná e sua influência na emergência e no vigor. Revista Brasileira de Sementes, 5:81-91.

Gray D, Steckel JRA \& Ward JA (1986) The effect of cultivar and cultural factors on embryo-sac volume and seed weight in carrot (Daucus carota L.). Annals of Botany, 58:737-744.

Leite VCA \& Hebling SA (2007) Efeito do ácido giberélico (GA $)$ e da luz na germinação in vitro de sementes de Cattleya warnerii T. Moore. Natureza Online, 5:55-62.

Maguire JD (1962) Speed of germination-aid in selection and evaluation for seedling emergence and vigor. Crop Science, 2:176-177.

Martinotto C, Paiva R, Santos BR, Soares FP, Nogueira RC \& Silva AAN (2007) Efeito da escarificação e luminosidade na germinação in vitro de sementes de cagaiteira (Eugenia dysenterica DC.). Ciência e Agrotecnologia, 31:1668-1671.

Murashige T \& Skoog F (1962) A revised medium for rapid growth and bioassays with tobacco tissue cultures. Physiologia Plantarum, 15:473-479.

Oliveira AF (2001) Enraizamento de estacas semilenhosas e cultura de embriões in vitro de oliveira (Olea europaea L.). Tese de Doutorado. Universidade Federal de Lavras, Lavras. 122p.

Popinigis F (1985) Fisiologia da semente. 2 ${ }^{\mathrm{a}}$ ed. Brasília, ABRATES. 298p.

Rugini E \& Caricato G (1995) Somatic embryogenesis and plant recovery from mature tissues of olive cultivars (Olea europea L.) "Canino" and "Moraiolo". Plant Cell Reports, 14:257-260.

Singh D (1981) The relative importance of characters affecting genetic divergence. The Indian Journal of Genetics and Plant Breeding, 41:237-245.

Taiz L \& Zeiger E (2008) Fisiologia vegetal. 4 ed. Porto Alegre, Artmed. 820p. 